\begin{tabular}{l|l|l|l}
$7^{\text {th }}$ CONGIC & $\begin{array}{l}\text { Blucher Design Proceedings } \\
\text { Setembro, 2015 - num. 2, vol.2 } \\
\text { proceedings.blucher.com.br }\end{array}$
\end{tabular}

\title{
O design da exposição Jovens Tipógrafos: das oficinas para a memória gráfica
}

\author{
The exhibition design of Young Typographers: from the crafts school to the Brazilian \\ graphics memory
}

\author{
Daniel Dutra Gomes, Letícia Pedruzzi Fonseca
}

exposição, história do design, artes gráficas, tipografia

Este artigo apresenta o design da exposição Jovens Tipógrafos: das oficinas para a memória gráfica. $O$ projeto visa apresentar à sociedade capixaba a história do Curso de Tipografia e Encadernação da antiga Escola Técnica de Vitória. O detalhamento técnico englobou a elaboração de padrões tipográficos para grandes formatos, a utilização da cor nos mais diversos suportes, a pluralidade de materiais envolvidos e suas limitações, noções de produção gráfica articuladas juntamente com os fornecedores e, ainda, um trabalho de produção audiovisual.

exhibition, design history, graphics arts, typography

This paper presents the exhibition design of 'Young Typographers: from the crafts school to the Brazilian graphics memory'. The project aims to present the history of the Typography and Binding Course from the Technical School of Vitória history to local society. The technical details included the development of typographical standards for large formats, the use of color in various media, the plurality of involved materials and their limitations, graphic production notions articulated together with suppliers and also an audiovisual production work.

\section{Introdução}

Em 2011, o Laboratório de Design: História e Tipografia (LadHT) investigou o Curso de Tipografia e Encadernação que funcionou entre 1942 e 1964 na Escola Técnica de Vitória (ETV), atual Instituto Federal do Espírito Santo (IFES). Pioneiro no ensino das artes gráficas na região, o curso teve relevante atuação no progresso do mercado gráfico capixaba.

Durante a pesquisa, não foi possível apresentar os resultados dessa investigação à sociedade. Desse modo, nasceu a proposta de projetar uma exposição para comunicar a história do Curso de Tipografia e Encadernação à comunidade.

A exposição intitulada Jovens Tipógrafos: das oficinas para a memória gráfica remonta à história do design local e, além de posicionar-se como uma oportunidade de entretenimento, configura-se como uma resposta à lacuna existente entre a prática profissional do designer e a sociedade capixaba.

D. D. Gomes, L. P. Fonseca. 2015. O design da exposição Jovens Tipógrafos: das oficinas para a memória gráfica. In: C. G. Spinillo; L. M. Fadel; V. T. Souto; T. B. P. Silva \& R. J. Camara (Eds). Anais [Pôster] do $7^{\circ}$ Congresso Internacional de Design da Informação/Proceedings [Poster] of the 7th Information Design International Conference | CIDI 2015 [Blucher Design Proceedings, num.2, vol.2]. São Paulo: Blucher, 2015. ISSN 2318-6968, DOI 10.5151/designpro-CIDI2015-congic_42 


\section{Método}

O percurso metodológico iniciou com a revisão teórica do design de exposição procurando compreender a sua prática (LOCKER, 2011) (HUGHES, 2010) (LORENC; SKOLNICK; BERGER), os elementos que compõe o espaço expositivo (BANNA, 1996), bem como refletir sobre o papel do designer na construção desses espaços (LAKE-HAMMOND \& WAITE, 2010) (HUGHES, 2010). (Figura 1):

A partir dessa revisão bibliográfica, estabeleceu-se o seguinte método para o projeto

Figura 1: Metodologia projetual.

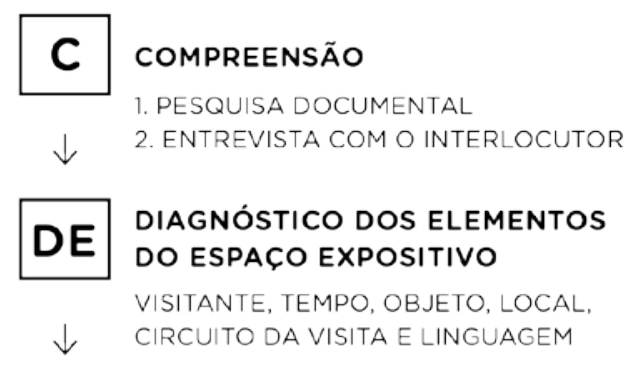

Briefing da exposição

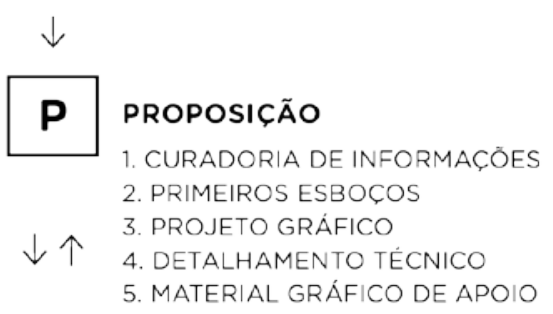

TV TESTEs E VALIDAÇÃo

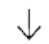

F finalização

\section{A exposição}

\section{Compreensão}

Inicialmente, desenvolveu-se uma pesquisa documental direcionada à encontrar mais detalhes sobre a história da ETV. Foram reunidos relatórios institucionais, boletins, programas de ensino, edições de jornais, decretos federais e editais oficiais.

Realizou-se, também, uma entrevista com o interlocutor do projeto: Ricardo Paiva, diretor-geral do IFES. O diálogo auxiliou no diagnóstico dos elementos do espaço expositivo visitante, tempo, objeto, local, circuito da visita e linguagem.

\section{Diagnóstico}

Segundo Hughes (2000), cabe ao designer elaborar estratégias para oportunizar ao visitante uma experiência significativa (HUGHES, 2010), sendo assim, importante pesquisar e

Anais [Pôster] do $7^{\circ}$ Congresso Internacional de Design da Informação | CIDI 2015

Proceedings [Poster] of the 7th Information Design International Conference | IDIC 2015 
compreender o público da exposição.

A partir da entrevista com o interlocutor, foram diagnosticados três perfis para o visitante da exposição: alunos do IFES; designers e artistas; e ex-alunos da antiga ETV. Realizou-se, então, entrevistas específicas com cada perfil do público-alvo para delinear suas intenções. É possível sintetizar o seguinte (tabela 1):

\begin{tabular}{l|l|l|l}
$\begin{array}{l}\text { Tabela 1: Necessidades e intenções do público-alvo. } \\
\text { Perfil do } \\
\text { visitante }\end{array}$ & Alunos do IFES & Designers e artistas & Ex-alunos da ETV \\
\hline $\begin{array}{l}\text { Necessidades e } \\
\text { intenções }\end{array}$ & $\begin{array}{l}\text { Imersão na Oficina de } \\
\text { Tipografia e Encadernação; } \\
\text { Discussão sobre a profissão } \\
\text { dos jovens tipógrafos. }\end{array}$ & $\begin{array}{l}\text { Exibição de peças } \\
\text { gráficas, máquinas; } \\
\text { A tipografia tratada } \\
\text { como obra de arte }\end{array}$ & $\begin{array}{l}\text { Apresentação do resgate } \\
\text { histórico; contato com a } \\
\text { pessoalidade nos objetos } \\
\text { expostos. }\end{array}$ \\
\hline Fruição & Pedagógica & Contemplativa & Saudosista \\
\hline
\end{tabular}

As entrevistas revelaram, ainda, o tempo médio entre uma e duas horas disponível para a visita à exposição. Não foi possível, no entanto, definir o local para a execução da exposição, o que possivelmente implicará em alterações na implantação do projeto.

O conceito da exposição é recriar o ambiente da Oficina de Tipografia e Encadernação, permitir ao visitante imergir na sala de aula dos jovens tipógrafos. Assim, estabeleceu-se para o circuito da visita uma orientação temática e não-sequencial.

O objeto da exposição é o conjunto formado por: fotografias antigas da escola; edições originais do jornal estudantil E.T.V.; convites de formatura da escola; máquinas e ferramentas utilizadas para o trabalho tipográfico; mesa de tipos; linotipos; guilhotina; impressoras; gravação em vídeo de entrevista com ex-aluno da ETV. Outros objetos foram elaborados na proposição formal da exposição.

Quanto à linguagem da exposição, o desafio é encurtar a distância histórica entre o visitante e os objetos da exposição. Para tanto, foram elaboradas situações que oportunizem a interação entre o público e os objetos. O produto final dessa segunda fase do projeto é um briefing, documento que reúne todas as informações da etapa de diagnóstico.

\section{Proposição}

Não houve uma curadoria rígida do conteúdo da exposição. A seleção dos textos e objetos iniciou-se em paralelo à etapa de compreensão e seguiu sofrendo alterações até o final do detalhamento técnico.

A partir das informações expostas no diagnóstico, foram esboçados três ambientes para a exposição: o Hall de entrada, a Oficina de Tipografia e Encadernação, a Vídeo instalação.

O Hall é o espaço inicial da exposição. A Oficina de Tipografia e Encadernação, por sua vez, é o segundo ambiente. Consiste em recriar a sala de aula dos jovens tipógrafos, permitindo ao visitante uma viagem no tempo e no espaço. A intenção é facilitar a interação do público com a história da ETV. O último espaço é a Vídeo Instalação. A idéia para este ambiente é exibir entrevistas com pessoas distintas do universo da tipografia, simulando uma "roda de conversa" entre os personagens, contrapondo suas experiências.

O trabalho seguiu com a estruturação do projeto gráfico da exposição. Segundo Locker (2011), é por intermédio do projeto gráfico que o visitante conecta-se com os espaços e suas mensagens.

A marca da exposição foi criada a partir da fonte Veneer, desenhada para comunicar aspectos visuais resultantes da técnica de composição por tipos móveis (Figura 2).

Anais [Pôster] do $7^{\circ}$ Congresso Internacional de Design da Informação | CIDI 2015 
Figura 2: Logotipo da exposição.

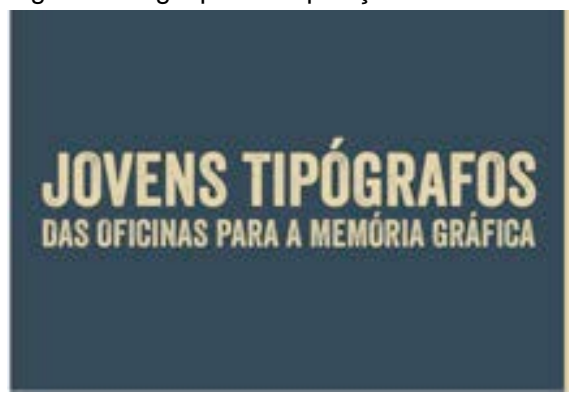

\section{JOVENS TIPÓGRAFOS DAS OFICINAS PARA A MEMÓRIA GRÁFICA}

Houve um cuidado com a utilização do texto no espaço expositivo. A partir da demanda de conteúdo identificada, foram adotados padrões no uso da família tipográfica Alright Sans (Figura 3), empregada na composição dos textos em três possibilidades: suportes verticais, suportes horizontais e placas de identificação. A Alright Sans foi escolhida por apresentar um ritmo de branco generoso e a altura-x levemente maior que a natural, sendo excelente para leituras distantes.

Figura 3: Padrões tipográficos.

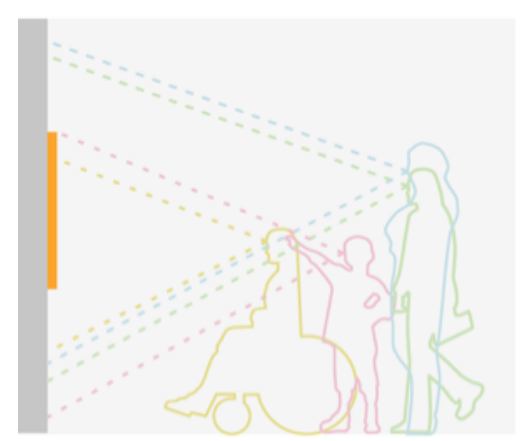

\begin{tabular}{l}
\hline PADRÃO TIPOGRÁFICO 1 \\
\hline TÍTULOS EM ALRIGHT SANS BOLD 120pt \\
TEXTO ALRIGHT SANS REGULAR 6O/90pt \\
CITAÇÖES EM CENTURY 6O/8Opt \\
\hline
\end{tabular}

COLUNAS DE TEXTO

Largura: $70 \mathrm{~cm}$

Altura: $100 \mathrm{~cm}$

Entre-coluna: $8 \mathrm{~cm}$

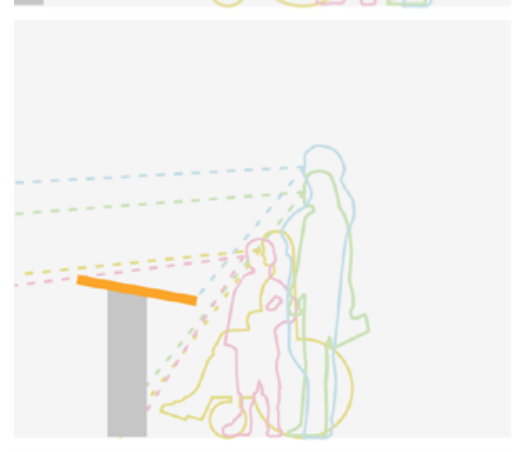

$\overline{\text { PADRÃO TIPOGRÁFICO } 2}$

TÍTULOS EM ALRIGHT SANS BOLD 48pt

TEXTO EM ALRIGHT SANS REGULAR 28/40pt CITAÇÕES EM CENTURY 28/36pt

COLUNAS DE TEXTO

Largura: $35 \mathrm{~cm}$

Altura: $28 \mathrm{~cm}$

Entre-coluna: $4 \mathrm{~cm}$

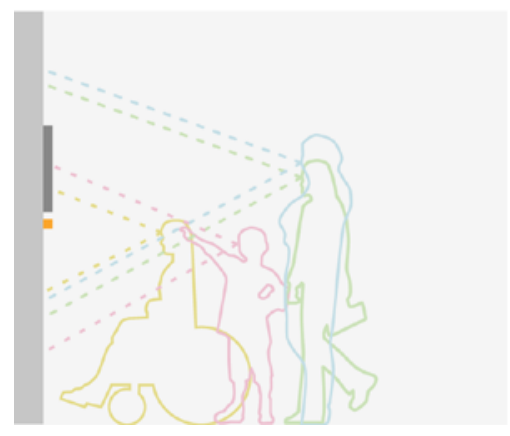

\section{PADRÃO TIPOGRÁFICO 3}

INFORMAÇÃO PRINCIPAL

EM ALRIGHT SANS BOLD 28pt

INFORMAÇÃO SECUNDÁRIA

EM ALRIGHT SANS REGULAR 18/24pt

Largura da linha: $20 \mathrm{~cm}$

Anais [Pôster] do $7^{\circ}$ Congresso Internacional de Design da Informação | CIDI 2015 Proceedings [Poster] of the 7th Information Design International Conference | IDIC 2015 
Foi elaborada, também, uma paleta cromática (Figura 4). Os tons foram selecionados de modo que fosse possível marcar as diferentes regiões da exposição e, paralelamente, tornar o espaço expositivo homogêneo como um todo.

Figura 4: Padrões cromáticos.

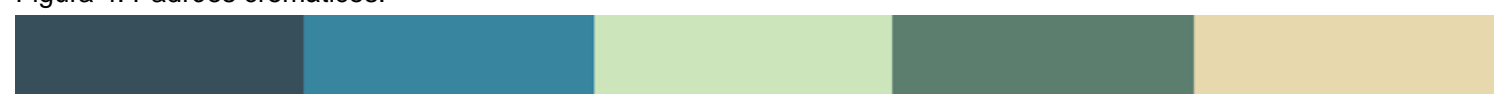

A seguir, será pontuado brevemente o detalhamento técnico dos ambientes. O Hall é constituído por três painéis:

- Apresentação da exposição (Figura 5);

- Edital de matrícula da ETV;

- Ficha técnica.

Figura 8: Painel de apresentação da exposição

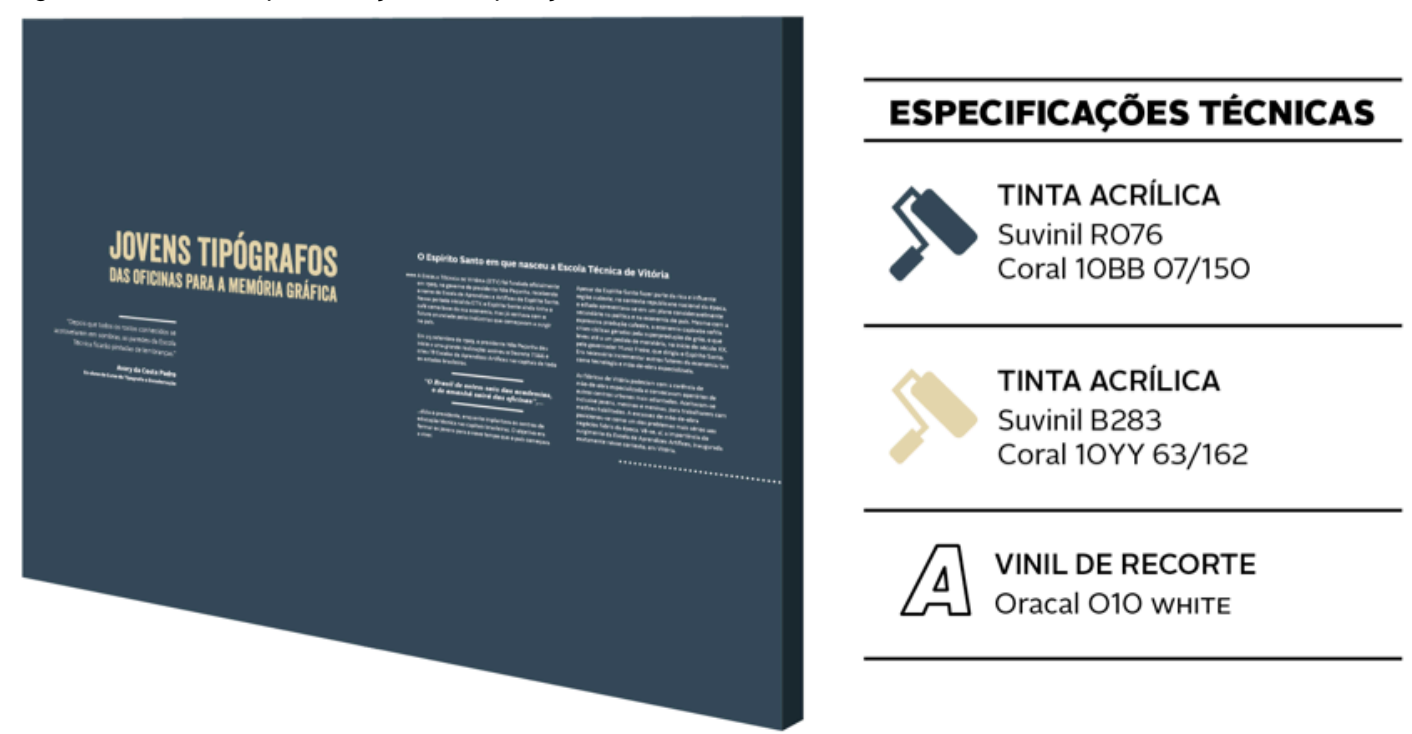

Para a Oficina de Tipografia e Encadernação, foram desenvolvidos:

- painel simulando um quadro-negro sobre o ensino da tipografia;

- mesa de professor exibindo vídeo de entrevista com ex-aluno da ETV;

- carteiras de estudantes com textos sobre o ensino da tipografia (Figura 9);

- painel com exemplos de famílias tipográficas;

- vitrines com edições do jornal E.T.V. e outras peças gráficas;

- fotografias antigas exibidas em caixas backlight (Figura 10);

- carimbos para o visitante simular a composição manual por tipos móveis;

- mesa de encadernação;

- placas e totens de identificação dos objetos. 
Figura 9: Carteiras de estudantes.

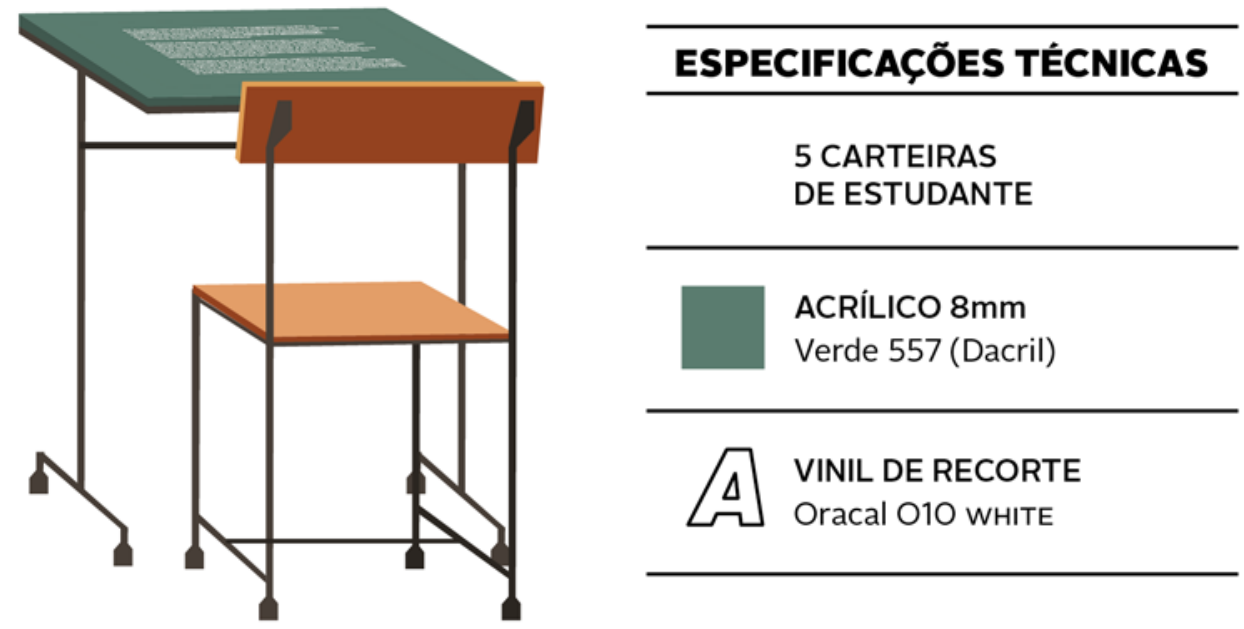

Figura 10: Backlights de fotografias.

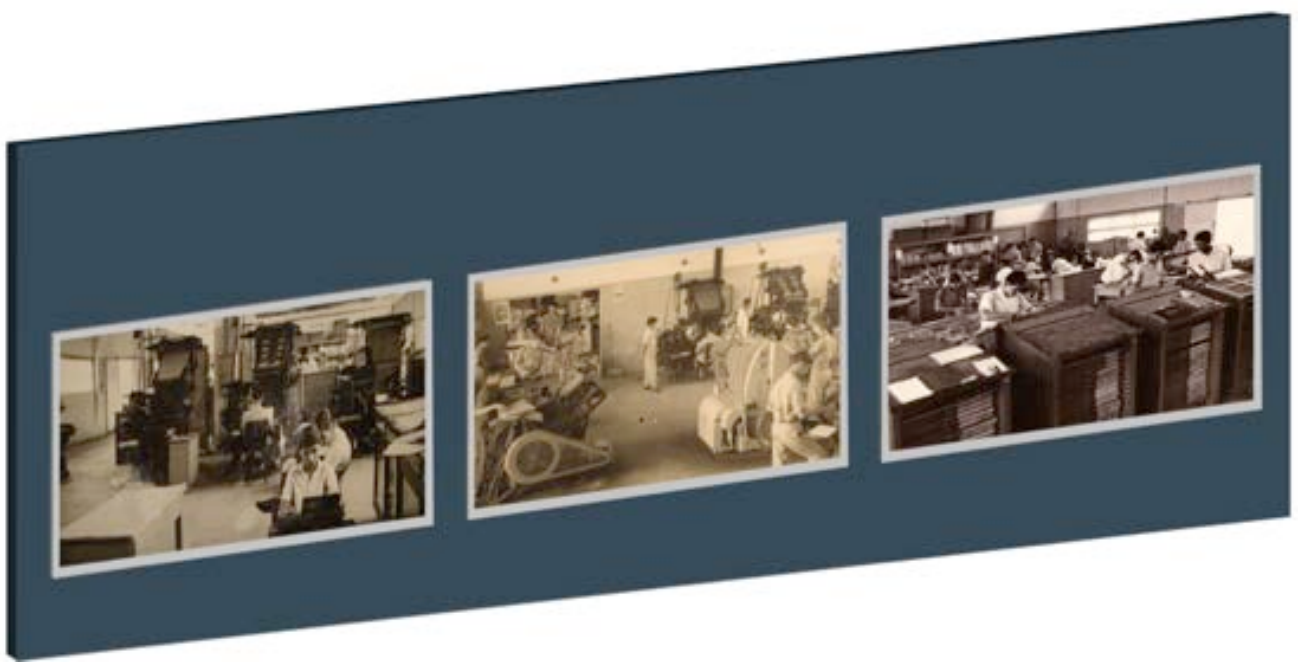

Os textos serão aplicados em vinil adesivo. Placas e totens de identificação, alguns painéis e outros objetos serão fabricados em acrílico. Os backlights, por sua vez, serão produzidos a partir de caixas com iluminação em LED e face em poliéster IM200.

A vídeo instalação reúne a exibição de entrevistas com Heliana Pacheco, professora de tipografia; Ricardo Esteves, designer de tipos; Oseas Wotkosky, ex-aluno da Oficina de Tipografia e Encadernação.

Uma vez que não há movimentação do entrevistado durante as filmagens, utilizou-se exclusivamente o plano italiano estático. A proposta é que cada personagem apareça em um quadro diferente, de modo que seja construído, metaforicamente, um diálogo entre os três vídeos (Figura 11). 
Figura 11: Proposta de estruturação da Vídeo Instalação.

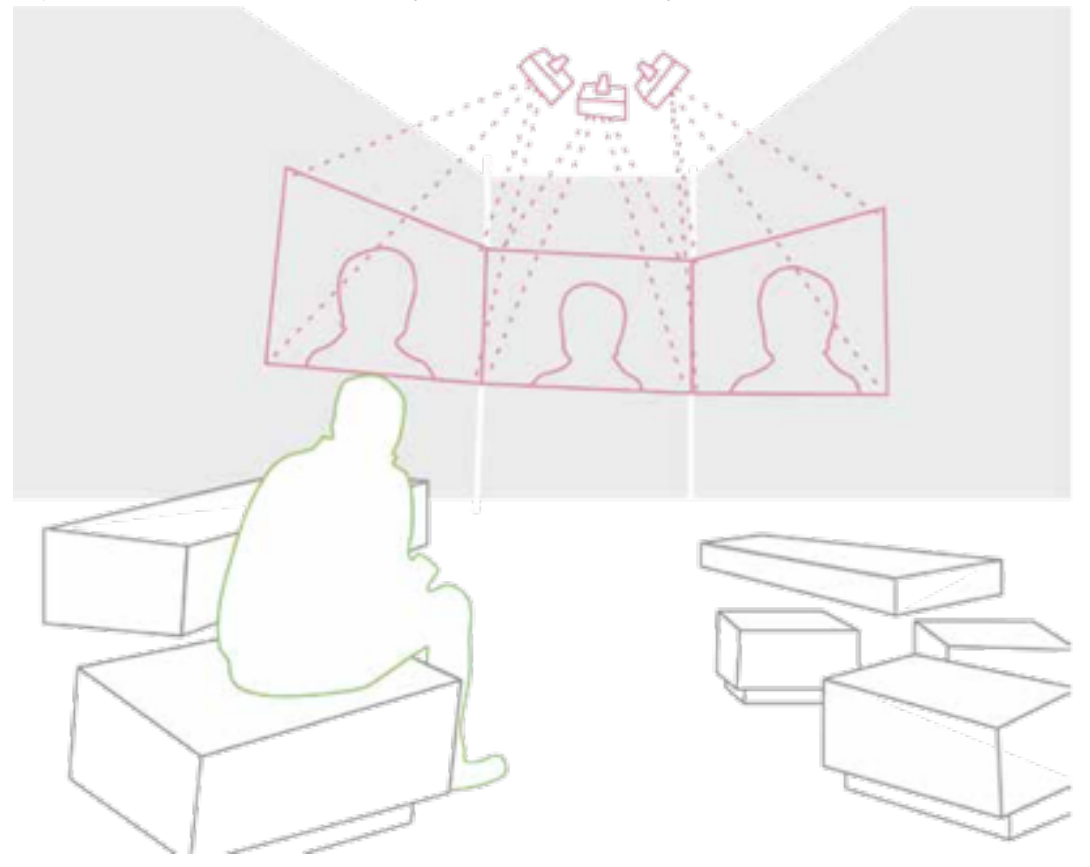

Foram elaboradas duas peças para o material gráfico de apoio: o convite da exposição e uma edição especial do jornal E.T.V.

O convite (Figura 12) apresenta o formato $20,0 \mathrm{~cm} \times 10,0 \mathrm{~cm}$. A impressão será feita no papel supremo duodesign $300 \mathrm{~g} / \mathrm{m} 2$ em $4 \times 1$ cores.

Figura 12: Mockup do convite da exposição.

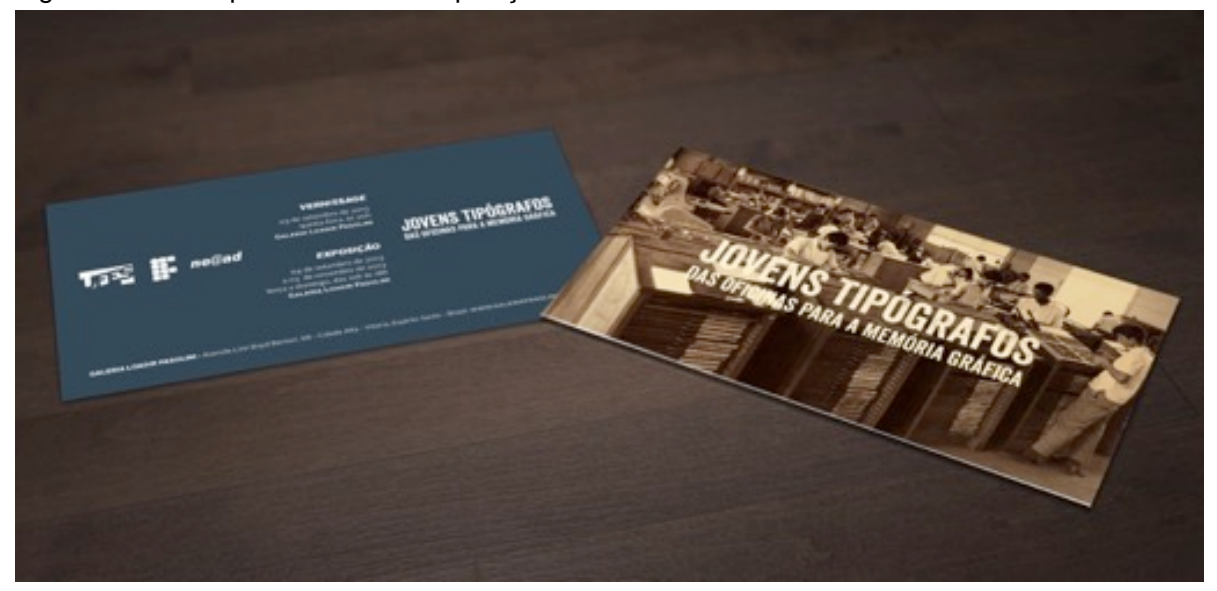

A edição do jornal (Figura 13) contém matérias de edições anteriores do folhetim, textos sobre a implantação das Escolas Técnicas e outras matérias redigidas a partir de publicações atuais sobre tipografia. A intenção é permitir ao leitor perceber como a prática da tipografia foi transformada no decorrer do tempo. O jornal tem 8 páginas no formato aberto de $44,0 \times 32,0 \mathrm{~cm}$. A impressão será em monocromia (preto) no papel pólen soft $80 \mathrm{~g} / \mathrm{m}^{2}$. 
Figura 13: Testes de impressão do jornal em diferentes papéis.

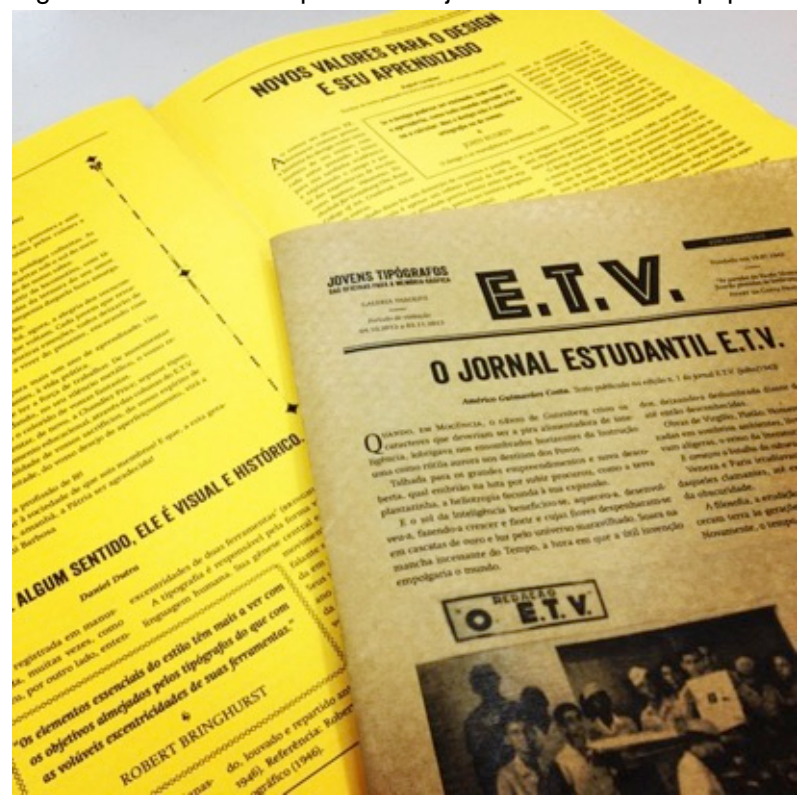

\section{Testes e validação}

Para desenvolver os padrões tipográficos, foram realizados testes seguindo orientações discutidas por Hughes (2010), sobre a leiturabilidade em espaços expositivos.

Os textos foram compostos em diferentes corpos (40,50, 60 e 80 pt) e observados a diferentes distâncias $(100,200$ e $500 \mathrm{~cm})$. O mesmo teste se repetiu para avaliar o comportamento da tipografia quanto a entrelinha, medidas da coluna de texto, altura mínima e máxima de visualização. A anatomia da Alright Sans discutida anteriormente garantiu boa leiturabilidade.

Quanto ao quadro cromático, a medida que este foi traduzido em diferentes códigos, foi necessário ajustá-lo a fim de que houvesse compatibilidade com o catálogo de materiais dos fornecedores locais.

Vale pontuar que o comportamento dos materiais definidos bem como as limitações de produção dos fornecedores também tiveram implicações importantes sobre a validação projetual, conduzindo inúmeros ajustes até a finalização do trabalho.

\section{Finalização}

Por fim, foi organizado um pacote de desenhos técnicos dos ambientes da exposição. Inclui diferentes vistas de cada item, perspectivas simuladas dos objetos, além das especificações dos materiais. Organizou-se, também, uma planilha orçamentária com os custos para a produção da exposição. A matriz registra os materiais, fornecedores e custos previstos.

\section{Considerações finais}

Um projeto de exposição revela o design da informação no seu sentido amplo. Antes de apresentar a informação no espaço expositivo, o designer tem a responsabilidade de selecionar

Anais [Pôster] do $7^{\circ}$ Congresso Internacional de Design da Informação | CIDI 2015

Proceedings [Poster] of the 7th Information Design International Conference | IDIC 2015 
e organizar a informação.

O trabalho de compreensão e diagnóstico dos elementos expositivos posicionam o design da informação como uma atividade que extrapola a formatação da informação, mas engloba também o planejamento das mensagens.

Na qualidade do discurso técnico, elaborado por uma linguagem estética complexa e múltipla, o designer tem o compromisso de garantir que todo o tipo de informação esteja acessível e utilizável na exposição.

Foram fundamentais o cuidado na elaboração dos padrões tipográficos para grandes formatos, a utilização da cor nos mais diversos suportes, a pluralidade de materiais envolvidos e suas limitações, as noções de produção gráfica articuladas juntamente com os fornecedores, o trabalho de produção audiovisual, os diálogos e o apoio com outros profissionais.

Projetar a exposição Jovens Tipógrafos: das oficinas para a memória gráfica proporcionou integrar pesquisa do design e prática projetual, conhecer e conjugar linguagens da ordem visual e plástica, e, por último, e porque não dizer particularmente mais nobre, registrar e contar a história do design capixaba.

\section{Referências}

BANNA, Nadia. 1996. La restructuration de la formation de guides pour une visite alternative. In: LEFEBVRE, Bernard, ALLARD, Michel. Le musée: un projet alternative. Montreal: Logiques.

HUGHES, Philip. 2010. Exhibition design. London: Laurence King.

LAKE-HAMMOND, A. WAITE, N. 2010. Exhibition design: bridging the knowledge gap. In The Design Journal. V. 13, n. 1. Berg Publishers.

LOCKER, P. 2011. Exhibition design. Lausanne: AVA Publishing.

LORENC, J; SKOLNICK, L; BERGER, C. 2007. What is exhibition design? Mies: RotoVision

\section{Sobre os autores}

Daniel Dutra Gomes, UFPE, Brasil <contato@danieldutra.com.br>

Letícia Pedruzzi Fonseca, UFES, Brasil <lepedruce@gmail.com>

Anais [Pôster] do $7^{\circ}$ Congresso Internacional de Design da Informação | CIDI 2015

Proceedings [Poster] of the 7th Information Design International Conference | IDIC 2015 